\title{
Public transportation graph: A graph theoretical model of public transportation network for efficient trip planning
}

\author{
Toplu taşıma çizgesi: Etkin seyahat planlaması için toplu taşıma ağının \\ çizge teorisi tabanlı bir modeli
}

\author{
Faruk SERIN $^{1}$ iD , Süleyman METE2 ${ }^{*}$ iD \\ ${ }^{1}$ Department of Computer Engineering, Faculty of Engineering, Munzur University, Tunceli, Turkey. \\ fserin@munzur.edu.tr \\ 2Department of Industrial Engineering, Faculty of Engineering, Gaziantep University, Gaziantep, Turkey. \\ suleyman489@gmail.com
}

Received/Geliș Tarihi: 27.05.2018, Accepted/Kabul Tarihi: 07.09.2018

doi: $10.5505 /$ pajes.2018.56873

* Corresponding author/Yazișllan Yazar Research Article/Araștırma Makalesi

\section{Abstract}

The presentation and usage of traditional graphs is very important for effective and fast solution of routing in public transportation. However, the traditional graph approach is unable to consider the passenger requests such as total travel time, minimum number of transfer and total distance of travel without pre-processing and/or post-processing. Moreover, the vehicles are not represented on traditional graph. In this paper, after analyzing the different kind of graphs, we propose a novel graph named as public transportation graph. The proposed graph models the public transportation system and considers distance, waiting time, travel time, self-transportation and number of transfers simultaneously for efficient trip planning. In this way, passenger requests can be met without pre-processing and post-processing. In addition, the vehicles are also considered and demonstrated in the proposed graph.

Keywords: Public transportation network, Graph, Multi-modal transportation, Trip planning

\section{Introduction}

Transportation is one of the most significant issue for aspect of city planners. It has a direct impact on the all aspect of the community such as education, economy, health and entertainment activities, and these cannot be maintained without an effective city infrastructure of transportation. Therefore, the importance of public transportation is increasing day by day with growing population. The most people generally prefer to use public transportation instead of their private car due to air and noise pollution, excessive and unreliable travel times, stress and traffic problems etc. Besides, although the choices of public transport users may be different from each other, the minimum number of transfers and the earliest arrival are the most important and common preferences within public transport users [1]. Therefore, number of transfers, total travel time and fee from origin to destination are important indicators for public transportation passengers. These indicators should be optimized according to passenger preferences.

There should be information on the traditional graph such as fee, transfer time, waiting time etc. for multi-objective network optimization. However, to the best of our knowledge, there are no graph representing all of these indicators together in the literature, hence, no pure solution algorithm (Dijkstra, $A^{*}$ etc.).
Öz

Geleneksel çizgelerin sunumu ve kullanımı, toplu taşımada etkin ve hızlı bir yönlendirme çözümü için oldukça önemlidir. Ancak, geleneksel çizge yaklaşımı, ön ve/veya son işlem olmaksızın yolcuların toplam seyahat süresi, asgari transfer sayısı, toplam seyahat mesafesi gibi isteklerini dikkate alamamaktadır. Dahası, geleneksel cizgelerde araçlar temsil edilememektedir. Bu çalışmada, farklı çizge türleri incelendikten sonra, toplu tașıma çizgesi olarak isimlendirilen yeni bir çizge önerilmiștir. Önerilen çizge etkin bir seyahat planlaması için toplu taşıma sistemini modellemekte ve mesafe, bekleme süresi, seyahat süresi, kendi kendine ulaşım ile transfer sayısını aynı anda göz önünde bulundurabilmektedir. $\mathrm{Bu}$ sayede ön ve son ișlem olmaksızın yolcu istekleri karșılanabilmektedir. Ayrıca, önerilen çizgede araçlar da göz önünde bulundurulmuş ve gösterilmiștir.

Anahtar Kelimeler: Toplu tașıma ağı, Cizge, Cok-modlu tașımacılık, Seyahat planlaması
Thus, we propose a novel public transportation graph to solve these problems as mentioned above. The main advantage of the proposed graph is to present the information of vehicles, time, fee and distance simultaneously. This paper proposes a novel multimodal transportation network graph for solving shortest path problem (SPP) in more efficiently and effectively considering preferences of passengers.

SPP is stated as the problem of finding a path from a source vertex to destination vertex in a graph with minimizing the cost. There are exact and polynomial time solution algorithms for the shortest path problem in the literature. SPP has been extensively applied in real life application such as traffic system, the transit path of passenger, car navigation system and transport path of hazardous material and so on [2]. There is extensive research related shortest path problems in the literature. Therefore, SPP and multimodal SPP literature are analyzed in detail chronology. Modesti and Sciomachen [3] analyzed shortest paths in multimodal transportation network with minimizing total cost. They presented classical shortest path approach based on a network defining the urban multimodal transportation system. A time-dependent intermodal optimum path algorithm is presented by Ziliaskopoulos and Wardell [4] for multimodal transportation network. The proposed algorithm is tested on realistic size network, and results show that algorithm is sufficient. The label correcting algorithm with imposing some simple domination 
conditions is improved by Skriver and Andersen [5] for solving the bicriterion shortest path problem. Moreover, they employ Dijkstra's algorithm with each parameter for finding the upper bounds on the objectives and set bounds on all labels. Lozano and Storchi [6] formulate a way to find shortest paths in a multimodal setting for the origin-destination pairs. Thus, the path is eliminated from on the sequence of used modes which are not comply a set of constraints. Bielli et al. [7] define a multimodal travel system designed to address the needs of a variety of demand-responsive transport. A transportation network modelling using geographic information systems and an algorithmic approach developed for solving multimodal SPP are proposed. Galvez-Fernandez et al. [8] propose an approach for multimodal transport problem with time-dependent. They define a new graph structure named as transfer graph, which complies the distributed nature of transportation network real information sources. A decomposition of the SPP in graph is suggested for optimizing the computation time. Raith and Ehrgott [9] consider bi-objective SPP as the natural extension of the single objective SPP. The objective of study is to compare the performance of different solution approaches and examine performance of these approaches on three types of networks. Abbaspour and Samadzadegan [10] focus the problem of multimodal SPP in complex and extensive urban areas with time dependent. An algorithm based on adapted evolutionary is used for solving the problem. The proposed approach is tested on real case of Tehran city, and three modes which are subway, bus and walking are employed to trip between points. Liu et al. [2] develop a genetic algorithm based on oriented spanning tree for solving multi- criteria SPP and multi-criteria constrained SPP. Proposed approach is analyzed on some computational test and results are compared with evolutionary algorithm. Later, simulated annealing algorithm is applied the same problem by Liu et al. [11]. Exact solution algorithm is investigated by Liu et al. [12] for solving multi-criteria multimodal SPP to minimize the total travel time and overall cost with transfer delayed. Designed algorithm with transfer delaying is based on exact label correcting algorithm, and effectiveness of the algorithm are tested on computing examples. Bowen and Ciyun [13] propose stochastic optimization approach based on iterative calculation of a valid route set for solving personalized urban multicriteria SPP. Results of the proposed approach are compared with genetic algorithm, and it is efficient and successful to solve the problem. Idri et al. [14] develop parallel distributed approach for solving SPP with dynamic multimodal transportation network. Liu et al. [15] present a new approach to simplify the mathematical formula of multimodal SPP under switching delay. Later, a developed label setting algorithm is proposed for solving the multimodal SPP in urban transit network.

The rest of the paper is given as follows: Material and method are analyzed in section 2 . In section 3 , the computational results are given and discussed. In last section conclusions are provided.

\section{Material and method}

Simple graph, which is also called a strict graph, is an undirected and unweighted graph. There is no graph loops or multiple edges in this type of graph [16]. An example of simple graph is demonstrated in Figure 1a. Directed graph, or digraph, has edges directed from one vertex to another. and no multiple edges or loops. In contrast, if the edges of graph are bidirectional, it is called as undirected graph (Figure 1b).
Weighted graph refers to an edge weighted graph that is each of edge has a numerical values or weights. Thus, a weighted graph is a special type of labeled graph in which the labels are numbers. A directed graph with weight on the edge of each graph are shown in Figure 1c. A multiple edge, which is also called parallel edges, is two or more edges that are incident on the same set of two vertices in a graph (Figure 1d). Moreover, the term of multigraph refers to multiple edge [17]. Dynamic graph differs from the static graph because it contains the time variable. For a static graph, this is basically $G=(E, V)$, where the graph $G$ is specified by a set of vertices $V$ and edges $E: V x V$. For a dynamic graph, $G_{0} ; G_{1} \ldots ; G_{t}$ is listed as an $N x N$ binary matrix for each time-point $t=0 ; 1 ; \ldots ; T$ but it is more memory-efficient to record instead the list of contacts and the time at which these contacts occur. For a dynamic network, a contact is a triple $(i ; j ; t)$ presenting the existence of an edge between nodes $i$ and $j$ (or from node $i$ to node $j$ in the directed case) at time $t$ [18]. Time-dependent graphs that travel time assigned to an edge is a function of the time of the day and it depends on departure time [19]. There are two questions that search the answer as (1) calculate the best connection for a given departure time and (2) calculate the all best connections during a given time interval (Figure 1e). Multimodal graph refers to graph that demonstrate two or more types of transportation modes such as riding a train, driving a car or walking, in a graph. Multiple connectivity groups are required to create a multimodal network graph (Figure 1f).

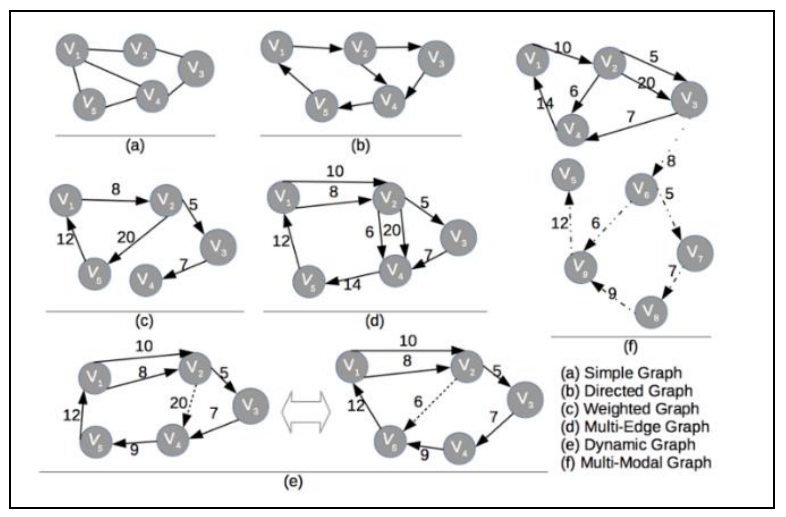

Figure 1: General graph types.

The modal of public transportation network is given in Figure 2. This network graph is included all graphs type except simple graph. The dash edge symbolized with $\mathrm{R}_{2}$ shows dynamic graph. There are two routes for two times. It is subjected to the schedule time while one of them is available in scheduled time, the second one is passive route. The dash edge symbolized with $\mathrm{T}_{1}$ indicates pedestrian/walking or different transportation mode as private car, bicycle. Moreover, dash edge shown with $\mathrm{T}_{111}$ represents changing mode. For example, while mode 1 $\left(\mathrm{M}_{1}\right)$ illustrates bus transportation network, mode $2\left(\mathrm{M}_{2}\right)$ can presents tram, metro or bus rapid transit etc. Thus, a passenger can change transportation modes from $\mathrm{M}_{1}$ to $\mathrm{M}_{2}$.

There are a lot of disadvantage of the graph shown in Figure 2. The first drawback, there is no information of time and vehicle on the graph. The second drawback, when network is considered as a multi objective, there is no information on graph such as fee, transfer time, waiting time etc. Lastly, basic solution algorithm (Dijkstra, $A^{*}$ etc.) cannot be applied in this network graph. To eliminate these drawbacks, some preprocessing and post-processing are required for solutions to the multimodal transportation network. 


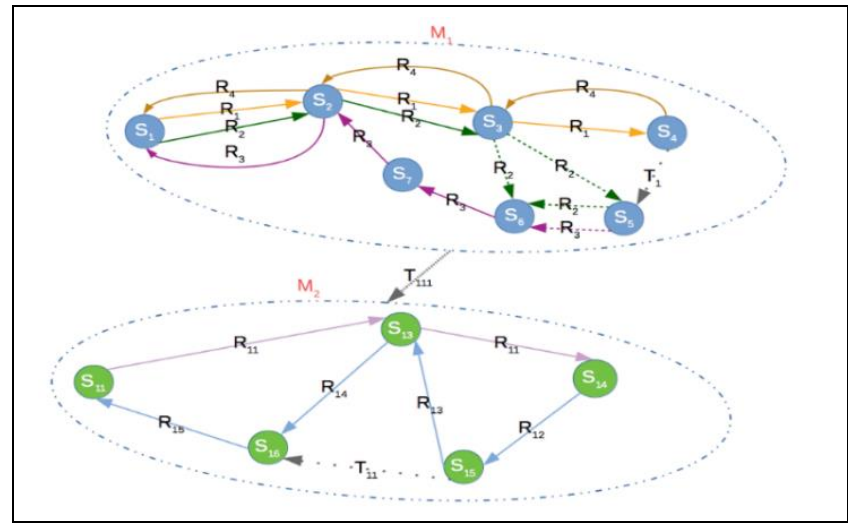

Figure 2: Multi-modal public transportation network.

We proposed a novel public transportation graph named as ostensive public transportation graph (OPTG) to solve these problems mentioned above. The main advantage of the proposed graph is to present the information of vehicles, time, fee and distance simultaneously. The information can be represented for transactional or analytical systems. The proposed graph is suggested especially for analytical systems. Thus, data duplication is acceptable to improve the efficiency of the solution algorithms.

An OPTG for two nodes is given in Figure 3 where (a), (b), (c), (d) show connectivity, distance, departure time and fee respectively. The abbreviations used in graphs are given as station $(S)$, route $(R)$, vehicle $(V)$, distance $(d)$, time $(t)$ and fee (f). The route and distances of three stations are presented in Figure 4 . The zeros $(0)$ on the second and fourth arcs are represent only connection with no cost.

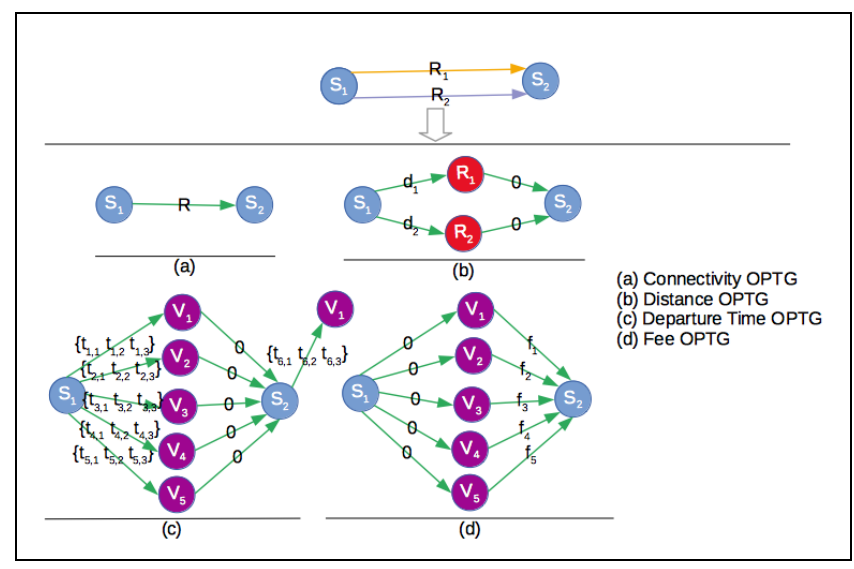

Figure 3: The parts of the proposed graph, ostensive public transportation graph (OPTG).

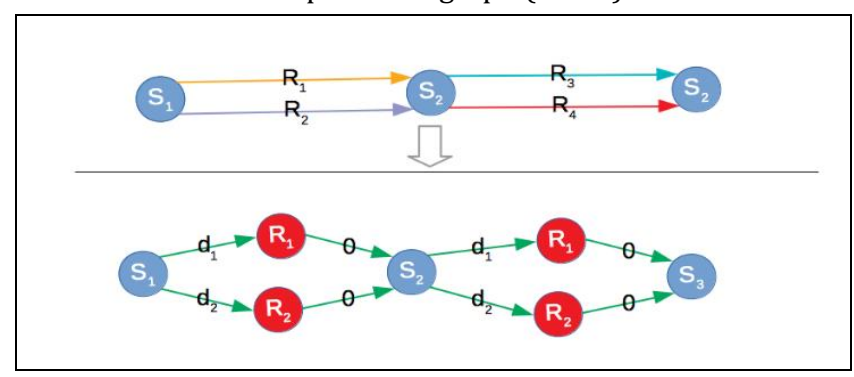

Figure 4: An OPTG having three stations with routes and distances.
Two routes and two stations for three objectives parameters (distance, time and fee) are illustrated for the proposed graph in Figure 5. For example, if the passenger prefers to minimum distance as objective, it is assumed that time and fee are equal zero to apply any solution algorithm(s) and vice versa.

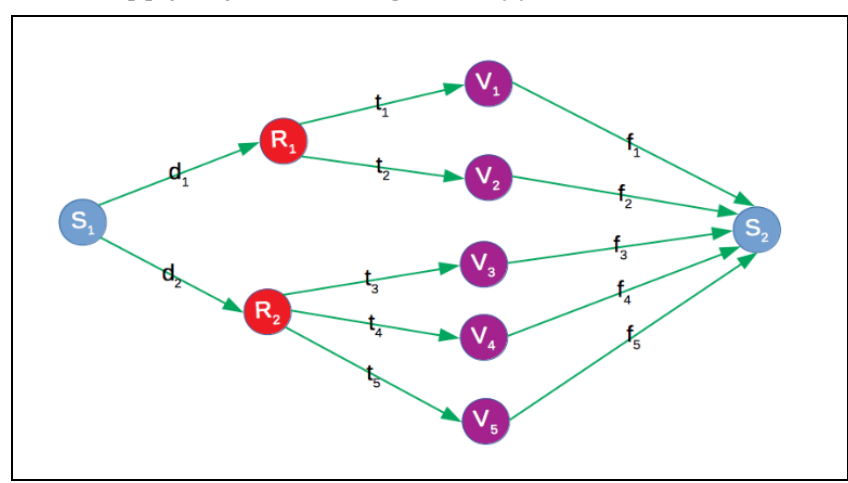

Figure 5: An example of the proposed OPTG.

\subsection{The calculation of objectives for the trip}

There are three types of vertex as stations, routes and vehicle and five types of arc in public transportation graph. The first type of arcs is named distance arc and it connects the stations to routes passing through the stations. While the second type of arcs connects the routes to vehicles working on the routes, the third type of arcs connects the vehicles to the stations. Fourth type of arcs is named as dynamic arc and it means that this arc is available only at specific times. Fifth type of arcs is named as transfer arc connecting two stations and it determines the distance between the stations.

The objective of the trip on the public transportation graph is calculated using distance, time, fee, number of transfers, and self-transportation. The distance between the stations varies regarding to route direction and the distance is determined on arcs from stations to routes. There are two types of time, which are departure time and arrival time. The departure time determines the time when vehicle departure from the station and it is determined on arcs from routes to vehicles. Stopover time is ignored in this case. Arriving time of the last station on route is required to be determined additionally as seen in Figure 6 as $S_{3}->R_{2}->V_{3}$. The fee of each route varies, and it is determined on the arcs from vehicles to stations. Route changing transfer (RCT) and route with stop changing transfer (RSCT) are considered as two types of transfer. The transfers can be inter-mode or inner-mode. The drop-off and pick-up stop are the same in RCT while not in RSCT. The transfer on RSCT is named as self-transportation, and can be performed by walking, car, bicycle, etc. RSCT is determined on arcs from station to station, and the weight of the arcs shows the distance between the stations.

Each cost parameters are updated in different arc types while traversing in the graph. The distance is updated on the distance arc and transfer arc. The total distance cost is calculated as in Equation (1). The time is updated on the time arc as total trip time and waiting time. The total time is sum of all intervals between departure and arriving times. The total time cost is calculated as in Equation (2). The waiting time is sum of all intervals between pick-up and drop-off times, and trip request time and trip start time. The total waiting time cost is calculated as in Equation (3). The fee is updated on fee arc if the vehicle change. The total fee cost is calculated as in Equation (4). The total self-transportation cost and transfer cost are calculated as 
in Equation (5) and Equation (6) respectively. The max value of the parameters is equal to or bigger than the maximum summed value of the parameter that can be observed on any trip. For example, if any trip can have maximum total distance of $10 \mathrm{~km}$, then the minimum value of $d_{\max }$ can be $10 \mathrm{~km}$.

$$
\begin{gathered}
F_{d}=\frac{1}{d_{\max }} \sum_{i=1}^{n_{d}} d_{i} \\
F_{t t}=\frac{1}{t t_{\max }} \sum_{i=1}^{n_{t t}} t t_{i} \\
F_{w}=\frac{1}{w_{\max }} \sum_{i=1}^{n_{w}} w_{i} \\
F_{f}=\frac{1}{f_{\max }} \sum_{i=1}^{n_{f}} f_{i} \\
F_{s t}=\frac{1}{s t_{\max }} \sum_{i=1}^{n_{s t}} s t_{i} \\
F_{t}=\frac{1}{t_{\max }} \sum_{i=1}^{n_{t}} t_{i}
\end{gathered}
$$

The objective of the trip $(F)$ is calculated by weighted sum of all objective parameters as in Equation (7) where $0 \leq \alpha_{d}, \alpha_{w}, \alpha_{t t}, \alpha_{f}, \alpha_{s t}, \alpha_{t} \leq 1$. The decision-maker can calculate the total trip cost by giving high weight to the more important parameters, and low weight to the less important parameters. Hence, decision makers can choice the best alternative by considering passenger preferences with given different priority for the objective function.

$$
F=\alpha_{d} F_{d}+\alpha_{w} F_{w}+\alpha_{t t} F_{t t}+\alpha_{f} F_{f}+\alpha_{s t} F_{s t}+\alpha_{t} F_{t}
$$

\section{Experimental results}

In this section, we present an illustrative and numerical example of OPTG to calculate the cost of different trips (see Figure 6). The example consists of 7 stations, 13 vehicles and 6 routes. For example, first and second arcs in station $\left(S_{1}\right)$ present the distance as 2 and $3 \mathrm{~km}$ respectively. While arcs between routes and vehicles indicate the departure time, arcs between vehicles and station $\left(\mathrm{S}_{2}\right)$ show transportation fee. Thus, all network for 7 stations are created with same manner (see Figure 6).

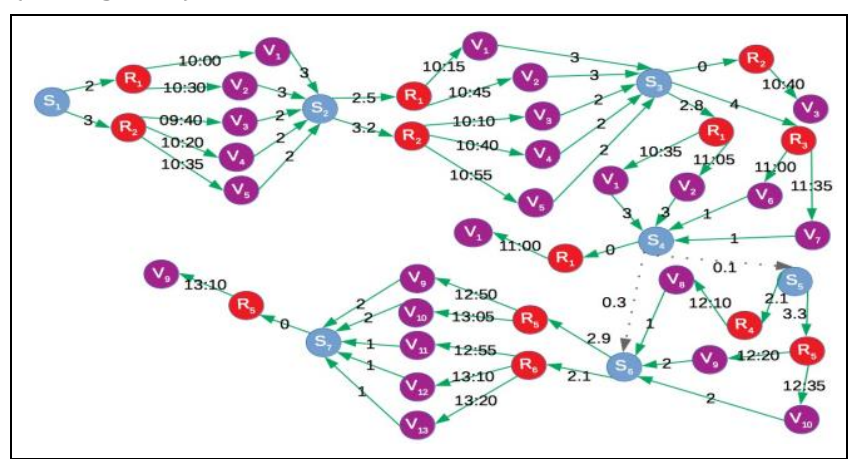

Figure 6: An illustrative example for proposed graph.

In Table 1, it is shown how to calculate the cost of trips for three alternative trips in OPTG of Figure 6 by considering distance, waiting time, travel time, self-transportation and number of transfers. The trip is assumed to start at 9.20 a.m. The aim of passenger is to arrive to $S_{7}$ from $S_{1}$. For example, In the alternative trip 1 , the passenger uses $R_{1}$ with $V_{1}$ to arrive $S_{4}$ from $S_{1}$. In this station $\left(S_{4}\right)$, passenger should change transfer mode or route (RCT) by changing station (from $\mathrm{S}_{4}$ to $\mathrm{S}_{5}$ ) using self-transportation (walking, private car, bicycle etc.). then, the

\begin{tabular}{|c|c|c|c|c|c|c|c|c|c|c|c|c|c|c|c|c|c|c|c|c|}
\hline \multicolumn{7}{|c|}{ Alternative Trip 1} & \multicolumn{7}{|c|}{ Alternative Trip 2} & \multicolumn{7}{|c|}{ Alternative Trip 3} \\
\hline $\mathrm{Tr}$ & $\mathrm{d}$ & $\mathrm{w}$ & tt & $\mathrm{f}$ & st & $\mathrm{t}$ & $\mathrm{Tr}$ & $\mathrm{d}$ & $\mathrm{w}$ & tt & $\mathrm{f}$ & st & $\mathrm{t}$ & $\operatorname{Tr}$ & $\mathrm{d}$ & $\mathrm{w}$ & $\mathrm{tt}$ & $\mathrm{f}$ & st & $\mathrm{t}$ \\
\hline $\mathrm{S}_{1}$ & 0 & - & - & - & - & - & $\mathrm{S}_{1}$ & 0 & - & - & - & - & - & $\mathrm{S}_{1}$ & 0 & - & - & - & - & - \\
\hline $\mathrm{R}_{1}$ & 2 & - & - & - & - & - & $\mathrm{R}_{2}$ & 3 & - & - & - & - & - & $\mathrm{R}_{1}$ & 2 & - & - & - & - & - \\
\hline $\mathrm{V}_{1}$ & 2 & 45 & - & - & - & - & $\mathrm{V}_{3}$ & 3 & 20 & - & - & - & - & $\mathrm{V}_{1}$ & 2 & 40 & - & - & - & - \\
\hline $\mathrm{S}_{2}$ & 2 & 45 & - & 3 & - & 0 & $\mathrm{~S}_{2}$ & 3 & 20 & - & 2 & - & 0 & $\mathrm{~S}_{2}$ & 2 & 40 & - & 3 & - & 0 \\
\hline $\mathrm{R}_{1}$ & 4.5 & 45 & - & 3 & - & 0 & $\mathrm{R}_{2}$ & 6.2 & 20 & - & 2 & - & 0 & $\mathrm{R}_{1}$ & 4.5 & 40 & - & 3 & - & 0 \\
\hline$V_{1}$ & 4.5 & 45 & 15 & 3 & - & 0 & $\mathrm{~V}_{3}$ & 6.2 & 20 & 30 & 2 & - & 0 & $\mathrm{~V}_{1}$ & 4.5 & 40 & 15 & 3 & - & 0 \\
\hline $\mathrm{S}_{3}$ & 4.5 & 45 & 15 & 3 & - & 0 & $\mathrm{~S}_{3}$ & 6.2 & 20 & 30 & 2 & - & 0 & $\mathrm{~S}_{3}$ & 4.5 & 40 & 15 & 3 & - & 0 \\
\hline $\mathrm{R}_{1}$ & 7.3 & 45 & 15 & 3 & - & 0 & $\mathrm{R}_{1}$ & 9 & 20 & 30 & 2 & - & 1 & $\mathrm{R}_{1}$ & 7.3 & 40 & 15 & 3 & - & 0 \\
\hline$V_{1}$ & 7.3 & 45 & 35 & 3 & - & 0 & $\mathrm{~V}_{1}$ & 9 & 20 & 55 & 2 & - & 1 & $V_{1}$ & 7.3 & 40 & 35 & 3 & - & 0 \\
\hline $\mathrm{S}_{4}$ & 7.3 & 45 & 35 & 3 & - & 0 & $\mathrm{~S}_{4}$ & 9 & 20 & 80 & 5 & - & 1 & $\mathrm{~S}_{4}$ & 7.3 & 40 & 60 & 3 & - & 0 \\
\hline $\mathrm{S}_{5}$ & 7.4 & 45 & 115 & 3 & 0.1 & 1 & $\mathrm{~S}_{5}$ & 9.1 & 90 & 150 & 5 & 0.1 & 2 & $\mathrm{~S}_{6}$ & 7.6 & 150 & 170 & 3 & 0.3 & 1 \\
\hline $\mathrm{R}_{5}$ & 9.4 & 45 & 115 & 3 & 0.1 & 1 & $\mathrm{R}_{4}$ & 11.2 & 90 & 150 & 5 & 0.1 & 2 & $\mathrm{R}_{5}$ & 10.5 & 150 & 170 & 3 & 0.3 & 1 \\
\hline$V_{9}$ & 9.4 & 45 & 115 & 3 & 0.1 & 1 & $\mathrm{~V}_{8}$ & 11.2 & 90 & 150 & 5 & 0.1 & 2 & $\mathrm{~V}_{9}$ & 10.5 & 150 & 170 & 3 & 0.3 & 1 \\
\hline $\mathrm{S}_{6}$ & 9.4 & 45 & 115 & 5 & 0.1 & 1 & $\mathrm{~S}_{6}$ & 11.2 & 90 & 150 & 7 & 0.1 & 2 & $\mathrm{~S}_{7}$ & 10.5 & 150 & 170 & 5 & 0.3 & 1 \\
\hline $\mathrm{R}_{5}$ & 11.4 & 45 & 145 & 5 & 0.1 & 1 & $\mathrm{R}_{5}$ & 14.1 & 90 & 150 & 7 & 0.1 & 2 & $\mathrm{R}_{5}$ & 10.5 & 150 & 170 & 5 & 0.3 & 1 \\
\hline$V_{9}$ & 11.4 & 45 & 145 & 5 & 0.1 & 1 & $\mathrm{~V}_{9}$ & 14.1 & 90 & 190 & 7 & 0.1 & 2 & $V_{9}$ & 10.5 & 150 & 190 & 5 & 0.3 & 1 \\
\hline $\mathrm{S}_{7}$ & 11.4 & 45 & 145 & 5 & 0.1 & 1 & $\mathrm{~S}_{7}$ & 14.1 & 90 & 190 & 7 & 0.1 & 2 & & & & & & & \\
\hline $\mathrm{R}_{5}$ & 11.4 & 45 & 145 & 5 & 0.1 & 1 & $\mathrm{R}_{5}$ & 14.1 & 90 & 190 & 7 & 0.1 & 2 & & & & & & & \\
\hline$V_{9}$ & 11.4 & 45 & 165 & 5 & 0.1 & 1 & $\mathrm{~V}_{9}$ & 14.1 & 90 & 210 & 7 & 0.1 & 2 & & & & & & & \\
\hline
\end{tabular}
passenger should use $\mathrm{R}_{5}$ with $\mathrm{V}_{9}$ to arrive $\mathrm{S}_{7}$ from $\mathrm{S}_{5}$. Thus, totally distance is $11.4 \mathrm{~km}$, waiting time is 45 minutes, fee is 5 dollars, walking distance (self-transportation) is $0.1 \mathrm{~km}$, number of transfers is 1 and total travel time is 165 minutes for alternative trip 1.

Table 1: Three alternative trips for illustrative example.

Tr: Trip, w: Waiting time, tt: Travel time, st: Self-transportation, f: Fee, d: Distance, t: The number of transfers. 
In similar way, calculation of the objective parameter is obtained for alternative trip 2 and 3 (see Figure 6 and Table 1). Although total distance of alternative trip 3 is lesser than alternative trip 1, total travel time of alternative trip 3 is bigger than alternative trip1. Besides, alternative trip 2 is bigger than alternative trip 1 and 3 according to total distance, waiting time, travel time, total fee and number of transfers. This is show that if the total travel distance is most important preferences for passenger, alternative trip 3 can be chosen. In this way, decision maker can select the best alternative by considering passenger preferences such as distance, fee, waiting time etc.

The value of each parameter is calculated in Table 1 step by step. The total cost of each objective is shown on the last row of the table for each trip. The normalized cost of each objective and the cost of each trip are calculated as follow.

Let the weights of all objectives are equals to 1 , $\alpha_{d}, \alpha_{w}, \alpha_{t t}, \alpha_{f}, \alpha_{s t}, \alpha_{t}=1$, and the normalization values

$$
\begin{aligned}
& d_{\max }=100, w_{\max }=200, t t_{\max }=240, f_{\max }=10, \\
& s t_{\max }=2, t_{\max }=3 . \text { Then, } \\
& F=F_{d}+F_{w}+F_{t t}+F_{f}+F_{s t}+F_{t} \\
& F_{1}=11.4 / 100+45 / 200+165 / 180+5 / 10+0.1 / 2+1 / 3 \\
&= 2.139 \\
& F_{2}=11.4 / 100+90 / 200+210 / 240+7 / 10+0.1 / 2+2 / 3 \\
&= 2.856 \\
& F_{3}=10.5 / 100+150 / 200+ 190 / 240+5 / 10+0.3 / 2+1 / 3 \\
&= 2.63
\end{aligned}
$$

In this case, the best trip is alternative trip 1 while the worst trip is alternative trip 2 according to objective function.

\section{Conclusion}

In this paper, a novel transportation graph is developed for solving shortest path problem more efficiently and effectively considering preferences of passenger. The number of transfers, travel time, waiting time, distance and fee are aimed to minimize in the proposed graph. In the developed graph, while data duplication is acceptable, it can be ignored due to improve the efficiency of the solution algorithm. In this study, decision maker can select the best alternative by considering passenger preferences such as distance, fee, waiting time etc. with proposed novel graph. In this way, passenger can gain advantages such as economic, time and less stress during their trip.

For future studies, it is planed to solve SPP in the developep transportation graph by using different solution algorithms such as genetic algorithm, Dijkstra, $A^{*}$, simulating annealing etc. Besides, efficient solution approaches can gain with hybridization of these algorithms

\section{References}

[1] Celik E, Bilisik ON, Erdogan M, Gumus AT, Baracli H. "An integrated novel interval type-2 fuzzy MCDM method to improve customer satisfaction in public transportation for Istanbul". Transportation Research Part E: Logistics and Transportation Review, 58, 28-51, 2013.

[2] Liu L, Mu H, Yang X, He R, Li Y. "An oriented spanning tree based genetic algorithm for multi-criteria shortest path problems". Applied soft computing, 12(1), 506-515, 2012.
[3] Modesti P, Sciomachen A. "A utility measure for finding multiobjective shortest paths in urban multimodal transportation networks". European Journal of Operational Research, 111(3), 495-508, 1998.

[4] Ziliaskopoulos A, Wardell W. "An intermodal optimum path algorithm for multimodal networks with dynamic arc travel times and switching delays". European Journal of Operational Research, 125(3), 486-502, 2000.

[5] Skriver AJ, Andersen KA. "A label correcting approach for solving bicriterion shortest-path problems". Computers \& Operations Research, 27(6), 507-524, 2000.

[6] Lozano A, Storchi G. "Shortest viable path algorithm in multimodal networks". Transportation Research Part A: Policy and Practice, 35(3), 225-241, 2001.

[7] Bielli M, Boulmakoul A, Mouncif H. "Object modeling and path computation for multimodal travel systems". European Journal of Operational Research, 175(3), 1705-1730, 2006

[8] Galvez-Fernandez C, Khadraoui D, Ayed H, Habbas Z, Alba E. "Distributed approach for solving time-dependent problems in multimodal transport networks". Advances in Operations Research, 2009,1-15, 2009.

[9] Raith, A, Ehrgott M. "A comparison of solution strategies for biobjective shortest path problems". Computers \& Operations Research, 36(4), 1299-1331, 2009.

[10] Abbaspour RA, Samadzadegan F. "An evolutionary solution for multimodal shortest path problem in metropolises". Computer Science and Information Systems, 7(4), 789-811, 2010.

[11] Liu L, Mu H, Luo H, Li X. "A simulated annealing for multicriteria network path problems". Computers \& Operations Research, 39(12), 3119-3135, 2012.

[12] Liu L, Yang J, Mu H, Li X, Wu F. “Exact algorithms for multicriteria multi-modal shortest path with transfer delaying and arriving time-window in urban transit network". Applied Mathematical Modelling, 38(9-10), 2613-2629, 2014.

[13] Bowen G, Ciyun L. "A personalized urban multicriteria shortest path stochastic optimization algorithm". Mathematical Problems in Engineering, 2015(1-8), Article ID 987358, 2015.

[14] Idri A, Oukarfi M, Boulmakoul A, Zeitouni K, Masri A. “A distributed approach for shortest path algorithm in dynamic multimodal transportation networks". Transportation Research Procedia, 27, 294-300, 2017.

[15] Liu L, Mu H, Yang J. "Toward algorithms for multi-modal shortest path problem and their extension in urban transit network". Journal of Intelligent Manufacturing, 28(3), 767-781, 2017.

[16] Weisstein EW. "Simple Graph.". http://mathworld.wolfram.com/SimpleGraph.html (15.05.2018).

[17] Post JV. "Multiple http://mathworld.wolfram.com/MultipleEdge.html (15.05.2018).

[18] Sizemore AE, Bassett DS. "Dynamic graph metrics: Tutorial, toolbox, and tale". NeuroImage, 180, 417-427, 2018

[19] Delling D, Katz B, Pajor T. "Parallel computation of best connections in public transportation networks". Journal of Experimental Algorithmics, 17, 1-4, 2012. 